\title{
Complication risks of invasive dental procedures in HIV/AIDS patients
}

\author{
Miftakhul Cahyati, Febrina Rahmayanti \\ ${ }^{*}$ Resident Department of Oral Medicine Faculty of Dentistry Universitas Indonesia \\ ${ }^{* *}$ Department of Oral Medicine Faculty of Dentistry Universitas Indonesia
}

\section{ABSTRACT}

A total number of people living with HIV reached since it was first reported. Indonesia is on the brink of rapidly worsening AIDS epidemic. Oral health was frequent problem among HIV-infected person. Opportunistic oral lesions and infections were often one of the first manifestations of HIV. The aim of this literature review were to discuss complication risks and management undergoing invasive dental procedures. Thereby, dentists have been expected to increase awareness for dental treatment needs for HIV-infected patients by pay attention to applied standard procedure. The complications of HIV-infected patients were reported minor, self-limiting, non-life threatening and readily treated. Treatment planning for the patient with HIV follows the same sequences as with other patients priorities are to assuage pain, restore function, prevent further disease and consider esthetic results. We concluded that no different complication risks between HIV-infected and non-infected. Dentists can provide care for HIV-infected patients with assessing the current immunosuppresion stage, intake systemic medications, opportunistic infection potential and minimize contagion possibility to dental care professional or other patients.

Key words: HIV, AIDS, complication risk, dental invasive

\section{INTRODUCTION}

The number of HIV patients in the whole world is reported as progressively increasing. A sharp increase is seen in East Europe, Middle Asia and East Asia with African Sub Sahara area as the globally largest area with HIV infected people. ${ }^{1,2}$ HIV epidemic, according to the World Health Organization data in the end of 2007, is decreased compared to 2005., ${ }^{1,3}$ Based on the report on Monitoring the AIDS Pandemic (MAP), up to June 2005, the number of HIV/AIDS patients in Indonesia is recorded as 7,098. 1,4,5 The cumulative number of HIV and AIDS cases up to 2008 March 31 according to the Directorate General of Infectious Disease Prevention and Environmental Health, Ministry of Health, Republic of Indonesia data released by Spiritia foundation, there are 6,130 HIV cases and 11.868 AIDS cases with 64 new HIV cases and 727 new AIDS cases. ${ }^{6}$ From the total number of drug users who join free HIV test held by Pokdisus AIDS of the Faculty of Medicine, Universitas Indonesia/ Cipto Mangunkusumo Central Hospital/RSUPNCM), it is revealed that $33 \%$ of them have HIV. ${ }^{7}$

Oral health is a frequent problem in HIV patients. ${ }^{8,9}$ This is supported by the fact that the opportunistic lesion and oral infection often become the first manifestation of HIV. ${ }^{8}$ Due to its 
effect to the immune system, HIV develops into a disease that affect all health aspect leading to increase health care needs, including dental care. $8,10,11$ In general, the awareness of HIV patients on their infection status also increase their awareness towards oral health which prompt their effort to improve their oral hygiene routinely and increase their frequency of dental or specialist visits. ${ }^{10}$ The number of HIV patient visits in the Oral and Dental Functional Service Unit of Cipto Mangunkusumo Central Hospital during 2006 is 28 patients who need invasive dental treatment covering 100\% scaling, $54 \%$ extraction, and $17,8 \%$ odontectomy.

Often the HIV patients do not receive routine dental treatment due to financial and social reasons. ${ }^{9}$ Several studies stated that almost $70 \%$ of dentists refuse or reluctant to give dental and oral services to HIV patients. ${ }^{12,13}$ This may be caused by the possibility of increased risk of HIV transmission and the HIV immunosupression condition that may increase potential complications in dental care. ${ }^{12,14}$

Based on the above facts, this paper will discuss the complication risks that may happen during invasive dental treatment procedure for HIV/AIDS patients and its management. Therefore, it is expected that the awareness of dentists towards the need of dental care of HIV patients will be increased by paying attention to the applicable standard procedure.

\section{Treament complication risk}

Dental care can be given to HIV patients without hospitalization. ${ }^{15}$ Based on the consensus of ADA (American Dental Association) 1994, there is not specific treatment modification recommended except for advance AIDS patients who are found in the situation where modification is needed such as patients have low $\mathrm{CD4}^{+}$lymphocyte level, a platelet level of $<60,000$ cells $/ \mathrm{mm}^{3}$, a neutrophil of $<500$ cells $/ \mathrm{mm}^{3}$ that need antibiotic prophylaxis and the advance AIDS patients who need good treatment plan. ${ }^{16,17}$ However, the complication risks of dental treatment may be found similar to immunocompetent people. ${ }^{18}$ The risk of prolonged bleeding time after surgery, delayed treatment, alveolitis, oral infection or other organs may happen after a surgical procedure. It is thought that the complication risks will increase in immunocompromized patients such as hemophilia, liver cirrhosis, or immune system dysfunction that may increase bleeding risk and immune system disorders. Therefore, the immunosuppresion condition experienced by HIV patients will bring similar complication risks to those diseases. ${ }^{18}$

The tendency that HIV patients experience complications during invasive dental treatment is still controversial. ${ }^{12}$ A retrospective study of 1,810 invasive dental treatments such as periodontal, restorative, endodontics, prosthodontics and surgical procedure performed by dentists to 331 HIV infected patients with substantial immunosuppresion with a CD4 $4^{+}$less than 200 cells/ $\mathrm{mm} 2$ shows that the complication is low, which is around $0.9 \%$. Simple dental extraction shows $4.1 \%$ complications while surgical extraction shows $11.8 \%$ complication especially for dry socket. ${ }^{12}$ Several studies show that prophylaxis reduces the risk of dry socket and HIV infected patients. ${ }^{12,18}$

Although in the study as specific complication risk of invasive dental surgery in HIV patients is not shown, in general HIV status is not a risk factor for complication. ${ }^{19}$ Rose et al. ${ }^{19}$ compared several surgical procedures including invasive dental surgery and suggested that the invasive dental surgery does not lead to mortality risk and that there is no significant difference between HIVinfected patients with those who are not infected by HIV.

Several studies indicate that dentists now tend to give dental care to asymptomatic HIV patients compared to AIDS patients although there are not many studies have shown the relationship of disease status and dental care. There are also contrast differences in the form of discrimination for HIV patients where $70 \%$ of dentists are not interested to manage an HIV infected patients. If the HIV severity is related to the increased complication incidence after treatment then the dentists should show greater attention when taking care of patients in advance state. ${ }^{12}$

A study that by Glick et al. ${ }^{12}$ involves 331 HIV infected patients from different cities who were observed for 1 year with a $\mathrm{CD}_{4}^{+}$cells of $<$ 200 cells $/ \mathrm{mm} 3$ to assess complications related to dental treatment. It turns out that there is no significantly different complications between HIV patients and non HIV patients. In addition, in this study the types of complication are reported that include bleeding complained by patients and those 
conditions that need medical attention such as post surgical pain, dry socket, delayed healing after surgery or dental extraction. ${ }^{12}$ Most other studies on dental care complication risk in HIV patients only discuss the risk of dental extraction. ${ }^{20,23}$

Several studies on post dental care complication that have been reported include studies on dental extraction which is a minor surgery that needs wound healing in soft tissue and hard tissue that may increase the risk for complication. However, the HIV positive patients generally receive post surgery antibiotics compared to non-HIV patients although the use of antibiotics here is not clear yet. ${ }^{24}$ Porter et al. ${ }^{21}$ suggested that routine prophylaxis in dental extraction HIV patients is not indicated. This opinion is supported by Dodson et al. ${ }^{24}$ who stated antibiotics utilization is not related to post extraction complication and the complication is not significantly different with non HIV patients because HIV patients get antibiotics therapy as prophylaxis for other infections.

Another complication is dry socket (3.7\%), post dental extraction bleeding, prolonged bleeding time and delayed healing but those complications have similar frequency as the non HIV patients. ${ }^{21,23}$ Viremia is an indicator of active virus replication that causes continual re-infection and damages CD4 $4^{+}$lymphocyte. It is believed that HIV positive patients have poor surgical results compared to non HIV patients due to immunosuppresion status and poor viral control. ${ }^{25}$ Average complication, based on Dodson et al. ${ }^{24}$ study, does not show any significant difference based on its HIV severity.

Until this moment, there is not much known about the complication risk of dental implant procedure in HIV patients. Several case studies show successful implant with a result of a stable implant and healthy surrounding soft tissue, no bleeding in periodontal probing and no dental bone support abnormality in X-ray image. ${ }^{25,27}$ Implant usage is considered because patients who use conventional dental prosthetic experience difficulty in adapting to the prosthetic. They shift to implant to get more comfort, stability, function and masticatory efficiency with better retention and support especially in complete mandibularmaxillary overdenture usage. ${ }^{28}$ The success of implant depends on implant location, patient cooperativeness, surgeon skills and consideration and the type of implant to be placed. ${ }^{29}$

A study done by Stevenson et al. ${ }^{28}$ in $29 \mathrm{HIV}$ patients who are $>18$ years old with a criteria of hemoglobin of $>8 \mathrm{~g} / \mathrm{dL}$, absolute neutrophil of $>750$ cells $/ \mathrm{mm}^{2}$, platelet count of $>75,000 /$ $\mathrm{mm}^{3}$, AST (aspartate transaminase) $<5$ times ULN (the Upper Limit of Normal), billirubin < 2.5 times ULN, alkaline phosphatase $<5$ times ULN, creatinine $<2.5 \mathrm{mg} / \mathrm{mL}$, then implants using two osseointegrated dental implants were applied. It is stated that after 6 month evaluation all implants are successful and there is no difference between HIV patients and non HIV patients based on the clinical response and bone integration with the dental implants measured using standard parameter.

The complication that has been reported after endodontic procedure is flare-up that makes up 3.2\% of the cases. A study made Quesnell et al. ${ }^{31}$ which is supported by Suchina et al..$^{32}$ compared the effect of endodontic treatment in HIV and non HIV patients that show similar cure rate and prognosis. Therefore, endodontic treatment can be used as an alternative in preventing dental loss and a standard treatment for HIV/AIDS patients with irreversible pulp diseases.

Complications reported after scaling and curettage are bacteremia with an incident of 7 out of 22 and fever in 5 of 22 patients. ${ }^{33}$ HIV patients may experience increased gingivitis risk and rapidly progressive periodontal disease with a therapeutic response that depends on the last HIV status, systemic medication intake for managing HIV itself, antibiotic intake and bad habits related to health. ${ }^{34,35}$

\section{Complication predisposing factors}

The immunocompromised status of HIV patients becomes a reason for inability of support, control and effective immune response towards exogene trauma making it highly risky for complication development after a surgery. ${ }^{10}$ Patton $^{36}$ stated that HIV patients show increased hematological abnormality risk increase where the risk for trombocytopenia, neutrophenia, lymphopenia, and anemia becomes the biggest in high average viral replication and/or immune deficiency consequence leading to opportunistic infection. Scully et al. ${ }^{37}$ stated that $20 \%$ of HIV patients with hemophilia experience post invasive 
dental care complication with insignificant difference with non HIV hemophilic patients. ${ }^{37}$

Although it is rare, bleeding expansion may happen despite the normal hemostasis. Immune trombositopenia is known as HIV complication making patients who undergo extensive surgical procedure may experience increased bleeding tendency that makes complete hemostatic function assessment before surgery necessary. Dental extraction in HIV patients who have a platelet count of $>50,000 / \mathrm{mm}^{2}$ and an $\mathrm{Hb}$ level of $\leq 7 \mathrm{~g} / \mathrm{dL}$ should be delayed. If the assay is impossible and extraction is really needed due to emergency situation, a simple bleeding time test can be performed by the dentist to see whether the hemostatic function is acceptable. Increased bleeding time ( $>9$ minutes) indicate the need for quantitative and qualitative platelet function assays. ${ }^{35}$

Several causes of immune trombositopenia in HIV/AIDS are: (1) opportunistic infection and fever that contribute to increased platelet change; (2) increased HIV viremia triggering immune complex deposition on the platelet surface and trigerring release by liver and lymph; and (3) hematopoesis disorder that reduces compensation ability towards increased platelet damage. ${ }^{36}$

\section{Possible/previously performed complication management}

Treatment provided may trigger several complications including hemostatic dysfunction that can be anticipated using platelet count, prothrombin time, partial thromboplastin time assays before an invasive procedure. In addition, antibiotic prophylaxiscan be provided if necessary. ${ }^{12}$ Several authors recommend routine prophylaxis before dental extraction in AIDS patients. Other authors stated that patients with $C D 4^{+}$count of $<100$ cells $/ \mathrm{mm}^{3}$ and long antiretroviral chemotherapy patients should undergo neutropenia evaluation. Patients should be given antibiotic prophylaxis before dental treatment management only when the absolute neutrophil count is less than 500 cells $/ \mathrm{mm} 3$, where patients do not get antibiotic prophylaxis for pneumonia or tuberculosis. ${ }^{10}$ Besides the above management measures, the treatment procedure should be modified based on financial factors, medical condition and patient's emotional state. ${ }^{12}$

\section{DISCUSSION}

The complication found in invasive dental treatment for HIV patients can be considered as only a few with a self limiting nature, rapidly managed and does not threaten the life of patients without coagulopathy and severe neutropenia. ${ }^{24,38}$ The complications may include dry socket, infection, post operation pain, prolong bleeding time and delayed healing that may be found in the dental practice..$^{38}$ The presence of oral lesion, smoking habit or B clinical status of HIV can be used to predict the occurrence of complication but it cannot be made into excuses for delaying dental treatment. ${ }^{10} \mathrm{~A}$ study by Campo et al. ${ }^{10}$ indicates that a dentist can perform dental care to adult HIV patients without severe immunosuppresion condition. It is not always necessary to give pre-surgical antibiotics routinely to all patients except for patients with neutropenia of $<500$ cells/ml or IDUs (Intravenous Drug Users) since they need it as a prophylaxis against bacterial endocarditis. Although the relationship between the immunosuppresion status with bacterial endocarditis development is not clear yet, some studies show high average bacterial endocarditis among IDU HIV patients compared to non IDU HIV patients. There is also an inverse relationship between the occurrence of bacterial endocarditis and lymphocyte CD4 $4^{+}$count. The use of HAART (Highly Active Anti Retroviral Therapy) reduces morbidity, mortality and hospitalization related to HIV infection. ${ }^{39}$

HIV patient treatment plan follows the same order as the general patients with a priority of diminishing the pain, returning restorative function, preventing further disease and considering esthetic results. ${ }^{35}$ Although there is no justification of dental treatment modification based on the HIV status, there are unique treatment considerations in HIV population by paying attention to the general oral health that affect systemic health. The treatment modification of HIV patients is almost the same with other medically compromised patients and proactive behavior in HIV patient dental treatment is recommended by emphasizing preventing effort. Besides, the dental treatment planning and priority is important and individual judgment is needed. Dentists should also emphasize good oral hygiene maintenance. ${ }^{16,35}$ 
With limited evidence-based data to support the routine needs of antibiotic protection to prevent bacterimia and septicemia in routine dental treatment and based on the advisory statement form ADA (American Dental Association) and AAOS (American Academy of Orthopedic Surgeons), it is stated that antibiotic prophylaxis is not a routine indication for most dental patients. ${ }^{17,39}$ The use of routine antibiotics is a contraindication and may become a predisposition for superinfection and drug resistance towards microorganism even though for patients with immunocompromized condition and/or have commorbidity such as prosthetic bone surgical infection, HIV, type 1 diabetes or malignancy may have high risk. For various conditions above, the American Heart Association, the American College of Cardiology Foundation and American Heart Association Task Force on Practice Guidelines recommend the use of antibiotic prophylaxis. ${ }^{15,39,40}$

Individual examination by considering the additional medical commorbidity, immuno suppresion condition, the length of working time, and hospitalization that may increase wound infection risk is needed in treating HIV patients. ${ }^{39,41}$ Indications for antibiotic prophylaxis do not only include the number of lymphocyte $\mathrm{CD}^{+}$but also in the case where the number is less than $200 / \mu \mathrm{l}$, patient's history should be reviewed. Antibiotic prophylaxis for invasive action is recommended for patients with PMNL count (Polymorphonuclear lymphocyte count) $<500 / \mu$ l. Neutropenic condition often becomes HIV infection complication and also attack $35-75 \%$ of AIDS patients. Decreased neutrophil count may disturb immune mechanism against invasive bacteria making neutropenia a significant risk factor for bacterial infection. ${ }^{17}$

\section{CONCLUSION}

Dentist can give oral and dental care to HIV/AIDS patients by considering the immunosuppresion level, medication therapy used, potential opportunistic infection and minimizing the possibility of HIV transmission from patient to dentist, staff or other patients because the risk of invasive dental care complication for HIV/AIDS does not different significantly to the non HIV/ AIDS patients.

\section{REFERENCES}

1. Global summary of the AIDS epidemic December 2005. AIDS epidemic. [update: 2005 Dec]. UNAIDS and WHO. [cited 2007 Jul 21]. Available from: www.who.org.

2. UNAIDS and WHO Joint Annual Report. 2005 Nov. [cited 2007 Jul 21]. Available from:www. who.org.

3. Global Summary of the AIDS Epidemic December 2007. [updated 2007]. UNAIDS and WHO. [cited 2008 Mei 26]. Available from: www. who.org.

4. UNAIDS/WHO Epidemiological Fact Sheet. 2006 [Update: 2006]. [cited 2007 Jul 21]. Available from: http://www.unaids.org.

5. Sugeng. Penyebaran HIV/AIDS Indonesia tercepat di dunia 2005. [cited 2007 Jul 21]. Available from: http://www.depkes.go.id/ index.php?option=news\&task=viewarticle\&sid $=1080$.

6. Statistik kasus HIV/AIDS di Indonesia. [cited 2008 Mei 26]. Available from: http://www. spiritia.or.id/Stats/jumlah.php 16.00 .

7. Perkembangan epidemi AIDS di Indonesia Yayasan Mitra Inti. 2005 [cited 2007 Jul 21]. Available from: http://situs.kesrepro.info/ pmshivaids/des/2005/pms02.htm.

8. Results of the HCSUS Study. Do people with HIV get the dental care they need? RAND. 2005. p. 1-5. [cited 2007 Jul 21] Available from: www. rand.org.

9. Brown JB, Rosenstein D, Mullooly J, O'Keefe RM, Robinson S, Chiodo G. Impact of intensified dental care on outcomes in human immunodeficiency virus infection. AIDS Patient Care STDS 2002;16(10):479-86.

10. Campo J, Cano J, del Romero J, Hernando V, Rodriques C, Bascones A. Oral complication risks after invasive and non-invasive dental procedures in HIV-positive patients. Oral Dis 2007;13(1):110-6.

11. Diz-Dios P, Vazquez-Garcia E, FernandezFeijoo J. Postextraction complications in HIVinfected patients. JDR 1998;77:533-4.

12. Glick M, Abel SN, Muzyka BC, DeLorenzo M. Dental complications after treating patients with AIDS. JADA 1994;125(3):296-301.

13. Cade JE. Some dental professionals still 
reluctant to treat HIV patients. HIV Clin 2002;14(2):13-4.

14. Sadowsky D, Kunzel C. Measuring dentist willingness to treat HIV positive patients. JADA 1994 June;125:705-10.

15. Mosca NG, Rose HA. HIV-positive patients: dental management considerations. Dent Clin North Am 2006;50(4):635-57,viii.

16. Shetty K. Recommendations for the dental management of HIV-infected children and adolescents. HIV Clin 2004;16(2):1,3-8.

17. Shirlaw PJ, Chikte U, MacPhail L. Oral and dental care and treatment protocols for the management of HIV-infected patients. Oral Dis 2002;8 Suppl 2:136-43.

18. Patton LL, Shugars DA, Bonito AJ. A systematic review of complication risks for HIVpositive patients undergoing invasive dental procedures. JADA 2002;133(2):195-203.

19. Rose D, Collins M, Kleban R. Complication of surgery in HIV-infected patients. AIDS 1998;12:2243-51.

20. Robinson P, Cooper H, Hatt J. Healing after dental extractions in men with HIV infection. Oral Surg Oral Med Oral Pathol 1992;74:426 30.

21. Porter SR, Scully C, Luker J. Complications of dental surgery in persons with HIV disease. Oral Surg Oral Med Oral Pathol 1993;75(2):165-7.

22. Dodson TB, Perrott DH, Gongloff RK, Kaban LB. Human immunodeficiency virus serostatus and the risk of postextraction complications. Int J Oral Maxillofac Surg 1994;23(2):100-3.

23. Dodson TB. Predictors of postextraction complications in HIV-positive patients. Oral Surg Oral Med Oral Pathol Oral Radiol Endod 1997;84(5):474-9.

24. Dodson T. HIV status and the risk of post-extraction complications. JDR Oct 1997;76(10):1644-52.

25. Achong RM, Shetty K, Arribas A, Block MS. Implants in HIV-positive patients: 3 case reports. J Oral Maxillofac Surg 2006;64(8):1199203.

26. Shetty K, Achong R. Dental implants in the HIV-positive patient-case report and review of the literature. Gen Dent 2005;53(6):4347; quiz 438,446.

27. Baron M, Gritsch F, Hansy AM, Haas R. Implants in an HIV-positive patient: a case report. Int $\mathrm{J}$
Oral Maxillofac Implants 2004;19(3):425-30.

28. Stevenson GC, Riano PC, Moretti AJ, Nichols CM, Engelmeier RL, Flaitz CM. Short-term success of osseointegrated dental implants in HIV-positive individuals: a prospective study. J Contemp Dent Pract 2007;8(1):1-10

29. Porter J, von Fraunhofer J. Succes or failure dental implants? A literature review with treatment considerations. General dentistry 2005:423-32.

30. WaltonR, FouadA. Endodontic interappointment flare-ups: A prospective study of incidence and related factors. J Endod 1992;18(4):172-7.

31. Quesnell B, Alves $M$, Hawkinson R, Johnson $B$, Wenckus $C$, Begole $E$. The effect of human immunodeficiency virus on endodontic treatment outcome. JOE 2005;31(9):633-6.

32. Suchina JA, Levine D, Flaitz CM, Nichols CM, Hicks MJ. Retrospective clinical and radiologic evaluation of nonsurgical endodontic treatment in human immunodeficiency virus (HIV) infection. J Contemp Dent Pract 2006;7(1):1-8

33. Lucartorto FM, Franker CK, Maza J. Postscaling bacteremia in HIV-associated gingivitis and periodontitis. Oral Surg Oral Med Oral Pathol 1992;73(5):550-4.

34. Committee on Research SaT. Periodontal considerations in the HIV positive patients. The Am Acad of Periodontol Sci 1994 April:19.

35. Abel S, Croser D, Fischman S, Glick M, Phelan J. Principles of oral health management for the HIV/AIDS patient. Dental Alliance for AIDS/HIV Care 2000;2:1,2,24

36. Patton LL. Hematologic abnormalities among HIV-infected patients: associations of significance for dentistry. Oral Surg Oral Med Oral Pathol Oral Radiol Endod 1999;88(5):5617.

37. Scully C, Watt-Smith P, Dios RD, Giangrande PL. Complications in HIV-infected and nonHIV-infected haemophiliacs and other patients after oral surgery. Int J Oral Maxillofac Surg 2002;31(6):634-40.

38. Patton LL. HIV disease. Dent Clin North Am 2003;47(3):467-92.

39. Shetty K. Bacterial endocarditis and antibiotic prophylaxis in HIV dentistry. HIV Clin 2007;19(2):9-11. 
40. Lockhart P, Loven B, Brennan M, Fox P. The evidence base for the efficacy of antibiotic prophylaxis in dental practice. JADA April 2007; 138:458-74.
41. Little J, Falace D, Miller C, Rhodus N. Dental management of the medically compromised patient. $6^{\text {th }}$ ed. Missouri: Mosby Inc.;2002. p. 227-34. 